\title{
ANALYSIS OF PROTOCOLS OF INDIAN SUBJEGTS ON TAT N ACH TEST ${ }^{1}$
}

\author{
VASANT S. TAMHANKAR \\ University of Poona
}

\begin{abstract}
The paper presents findings regarding the relationship between length of protocol and $\mathrm{n}$ Ach scores, cue value of pictures, and analysis of subcategories. $S \mathrm{~s}$ were 1072 tenth grade boys of average and above average intellectual capacity, from high schools in Poona city, with a mean age of 15.80. They were given the 4-picture $\mathrm{n}$ Ach test under neutral condition. A significant positive correlation was found between length of protocol and n Ach scores. The "Inventors" picture elicited maximum achievement imagery, and the "Father-son" and "Operation scene" showed very low cue values. Analysis of subcategories indicated that the fantasy responses of Indian subjects were not "culturally" different in any conspicuous way from such responses observed in other cultures.
\end{abstract}

As important as the measured strength of achievement motivation, are other characteristics of the fantasy response such as length of protocol in relation to $\mathrm{n}$ Ach scores, cue value of pictures, analysis of subcategories, etc. These aspects may reveal cultural differences, if any, in responsiveness to life situations depicted in the thematic pictures, and in the modes of expression of the subjects. This paper presents some findings in this regard from the analysis of stories written by Indian subjects.

Some of the previous researchers (e.g., Atkinson, 1950 ; McClelland et al., 1953; Lesser et al., 1963) had reported that achievement content of stories written by subjects was not systematically related to the length of the stories; while some others (e.g., Ricciuti \& Clark, 1954 ; Ricciuti \& Sadacca, 1955; Scott, 1956; Walker \& Atkinson, 1958 ; Child et al., 1958 ; Veroff et al., 1960) obtained significant positive correlations between motive scores and verbal fluency, and thought it desirable to correct the scores for length of protocol. On the whole it was observed that the sig-

1. This paper has been adapted from the $\mathrm{Ph}$. D. Thesis of the writer submitted to the University of Poona, India. nificant correlation was the result of heterogeneity of samples and shorter time for writing stories; but correlations were "... insignificant and negligible when leading questions are employed and four minutes are alloted for each story " (Atkinson, 1958, p. 837). These findings are re-examined in the light of the data obtained in this investigation.

That pictures differ in their cue value in eliciting achievement imagery was noted by McClelland et al. (1953), Jacobs (1958), Birney (1958), and Haber \& Alpert (1958), by using methods either dependent on or independent of the achievement responses. Here a comparison of their results is made with the present results, not by using any independent method, but by ranking the pictures used in terms of the amount of achievement imagery elicited by them.

With an interest in the type of achievement imagery occurring under nonexperimental conditions, McClelland (1961) analysed the subcategories in stories from children's readers and found that achievement-related stories from more rapidly developing countries gave more 'successful instrumental activity' and 'obstacles' responses than the less rapidly developing countries. This was taken to mean that the higher $\mathrm{n}$ Achievement is more apt to be 
"means" oriented rather than goal oriented and often dwells in terms of means to overcome the obstacles. Mehta (1967) found that certain negative subcategories like negative affective states, obstacles, etc. are altogether absent in the protocols of Indian subjects. Here are presented the findings of another investigation attempting to search for the presence or absence of certain categories of the $\mathrm{n}$ Ach scoring system in protocols of Indian subjects.

\section{Method}

Sample

The $S$ s were 1072 tenth grade boys from 16 Marathi-medium high schools in Poona city. The selection was made by the classteachers and Heads of the schools who were asked to select, on their judgment, boys of average and above average intellectural capacity. ${ }^{2}$ The age range was 13.5 to 18 years with a mean of 15.80 .

\section{Procedure}

The 4-picture $\mathrm{n}$ Achievement test of 20 minutes was administered to all the boys by the writer himself. The pictures were: 1) Inventors (workshop scene), 2) Boy in checked shirt, 3) Father-son, and 4) Operation scene (McClelland et al., 1953). Instructions were the same as given under neutral condition, and boys wrote Marathi stories in response to the pictures projected on a white screen in the classroom.

\section{Scoring and Reliability}

Protocols were scored according to the conventions of the newly developed Marathi Manual (Tamhankar, 1967) for scoring $n$ Achievement (system $\mathrm{C}$ ). To compute the $\mathrm{n}$ Ach score, +1 was given for Achievement Imagery (AI), 0 for Doubtful or Task Imagery (TI), and -1 for Unrelated Imagery (UI).

\footnotetext{
${ }^{2}$ As none of the schools had any data on IQs or other measures of intelligence, the writer had to depend on the judgments of the teachers. Administering intelligence test was not possible under the conditions.
}

Subcategories were scored only if AI could be scored. Each subcategory was scored +1 , and only once per story, thus taking the maximal score possible for a single story to +11 (AI, N, I, Ga+, Ga-, Bp, Bw, Nup, G+, G-, and $\mathrm{Th}$ ). The $\mathrm{n}$ Ach score for a particular subject was the algebraic sum of the scores obtained on all the four stories written by him. Every tenth protocol was scored by another scorer (Mrs. VSK) who had taken a Master's degree in psychology, and the inter-scorer reliability of this scorer and the wirter was .85 .

\section{Results And Discussion}

\section{Length of Protocol and $n$ Achievement}

To study the relationship between verbal fluency and $\mathrm{n}$ Ach scores, the number of words in all the four stories for each of the 1072 subjects was counted. Incomplete protocols, not giving all the four stories and containing less than 100 words, were already discarded. The total number of words per protocol ranged from 107 to 510 with a mean of 288.12 words and $S D$ of 61.78. This range was divided into eight groups with a class interval of 40 words. The mean $n$ Ach scores for the eight groups according to length of protocol are given in Table 1.

The increasing means along with increasing length of protocol indicate a clear positive relationship between the two. The product-moment correlation between the achievement motivation scores and length of protocol was $+.235(\mathcal{N}=1072)$ which is, though low, highly significant at .001 level.

Our supposition was that the $\mathrm{n}$ Ach scores would not be related to length of protocol since all the subjects came from the same educational standard, had a limited age range, and were given leading questions and about $4 \frac{1}{2}$ minutes per story. However, it must be conceded, this supposition based on presumed homogeneity of the sample proved to be misconceived as indicated by the significant positive correla- 
TABLE 1

Mean n Ach scores and $S D$ s of subjects grouped according to length of protocol

\begin{tabular}{c|rrrrrrrrr}
\hline $\begin{array}{c}\text { Length of protocol } \\
\text { (number of words) }\end{array}$ & $\begin{array}{c}\text { Below } \\
180\end{array}$ & $180-219$ & $220-259$ & $260-299$ & $300-339$ & $340-379$ & $380-419 \begin{array}{c}420 \text { and } \\
\text { above }\end{array}$ \\
\hline Mean n Ach score & 2.21 & 2.91 & 3.61 & 4.26 & 5.76 & 6.51 & 6.64 & 5.87 \\
$S D$ & 4.31 & 4.60 & 4.65 & 5.01 & 5.73 & 5.99 & 5.00 & 4.01 & 24 \\
$\mathcal{N}$ & 34 & 105 & 227 & 284 & 222 & 120 & 56 & 24
\end{tabular}

TABle 2

Mean number of words per story written in response to each of the four pictures

$(N=1072)$

\begin{tabular}{c|cccc}
\hline & \multicolumn{3}{c}{ Picture } & 3 \\
\hline Mean number of words & 1 & 2 & 73.20 & 75.79 \\
$S D$ & 65.67 & 73.27 & 17.39 & 18.01
\end{tabular}

Tabte 3

Analysis of variance for length of stories

\begin{tabular}{c|crcc}
\hline Source of variation & \multicolumn{1}{c}{ Sum of squares } & $d f$ & Mean square & $F$ \\
\hline Between means & 61623.60 & 3 & 20541.20 & $15.94 *$ \\
Within means & 1376019.20 & 1068 & 1288.41 & \\
\hline Total & 1437642.80 & 1071 & & \\
\hline
\end{tabular}

* Significant at .01 level.

TABLE 4

Results of $i$-test of significance applied to the differences between mean number of words per story written in response to each of the four pictures

$(N=1072)$

\begin{tabular}{c|c||c|c}
\hline Between & $C R$ & Between & $C R$ \\
\hline Picture 1 and 2 & $9.71 * *$ & Picture 2 and 3 & 0.09 \\
$", 1$ and 3 & $9.57 * *$ &, 2 and 4 & $3.31 *$ \\
\hline$\quad 1$ and 4 & $12.66 * *$ &, 3 and 4 & $3.39 *$
\end{tabular}

* Significant at 01 level.

** Significant at .001 level.

tion. To explain the positive relationship, we can only say that verbal productivity does seem to facilitate the expression of $n$ Achievement even among subjects with the same schooling and when tested under the most standard conditions. This leads us to reiterate the need of ascertaining the relationship in the very beginning and making the necessary adjustments in the raw $\mathrm{n}$ Ach scores.

A secondary interest was to see whether stories written in response to the four pic- 
tures differed in length from one another significantly. For this, the mean number of words in stories on each of the four pictures was calculated. The mean number of words and $S D \mathrm{~s}$, the analysis of variance, and the significance of the differences between every two means are given in Table 2, 3, and 4 respectively.

From Table 3 it is clear that the stories do differ in length significantly. Further, on applying the $t$-test of significance, if was found that 5 out of the 6 differences were highly significant beyond .01 level as shown in Table 4. More interesting to note is the fact that the length of stories (mean number of words) is smallest for the first picture, about the same for the middle two pictures, and greatest for the last picture. On the contrary, the mean $n$ Ach score for the four pictures, as will be seen subsequently, goes on decreasing. Here is an apparently paradoxical situation. In the previous paragraphs it was noted that so far as the individual subjects are concerned, there is a significant positive correlation between total length of protocol and the $n$ Ach scores; but now we see that so far as the stories in response to the four separate pictures are concerned, there is, in general, an inverse relationship between length of stories and scores yielded by the four pictures. In other words, longer protocols have given highn Ach scores; but longer stories in response to a particular picture have yielded a low $n$ Ach score. How to explain? It is felt that the two relationships should not be related to each other or to some third common factor, but should be explained in different contexts.

The projective test under darkroom conditions was quite a novelty to high school boys, and it is possible that they took some time for incitement and adaptation to the test situation. This might have resulted in eliciting relatively shorter stories in response to the first picture. As is seen from Table 2 , stories in response to the next two pictures which are in the middle of the TAT have almost the same length. For the last picture, the students were aware that the test was coming to an end soon, and probably therefore they might have done their best to write as much as possible within the stipulated time. The somewhat longer stories on the last picture may thus be an indication of the 'end spurt' but without any advantage for the $\mathrm{n}$ Ach score.

The mean $n$ Ach scores on stories written in response to the four different pictures are primarily a function of the cue characteristics of pictures, and are not much related to length of those stories as such. In any case we have to hold with the overall positive relationship between total length of protocol and $\mathrm{n}$ Ach scores.

A comparison of these findings regarding length of protocol with those of Veroff et al. (1960) is pertinent. The product-moment correlation between length and $\mathrm{n}$ Ach scores obtained here $(r=+.235, \mathcal{N}=1072)$ is very near to the correlation reported by the said authors $(r=+.28, \mathcal{N}=597)$. The median length of protocol they observed was 291 words for six stories or about 48 words per story when four minutes per story were given for writing; whereas the median length of protocol for only four stories in the present study is 285.63 words, or 71.41 words per story when $4 \frac{1}{2}$ minutes per story were given. On further analysis according to the level of education, Veroff et al. found that subjects educated upto the high school stage had a mean of 276.2 words per protocol of six stories, whereas our high school boys have a mean of 288.12 words per protocol of only four stories. At the outset it seems that the subjects of the present study have written longer stories than the subjects of Veroff et al. Here arises the question of the comparative expressive power of the two languages-English and Marathi.

It is often argued that English is more expressive than Marathi in the sense that what one has to say can be said in fewer words in the former language than in the latter. This may be true from the literary point of view; but in the context of our limited problem, we tried to study the facts 
TABLE 5

Percentages of achievement-related (AI) stories on the four pictures, and the mean $n$ Ach score per story

$(N=1072)$

\begin{tabular}{l|rrrr}
\hline & \multicolumn{3}{c}{ Picture } & \multicolumn{1}{c}{4} \\
\hline Percentage of (AI) stories & 1 & 2 & 34.70 & 24.44 \\
Mean n Ach score & 51.03 & 42.44 & 0.71 & 0.53
\end{tabular}

TABLE 6

Significance of the differences between percentages of achievement-related stories on the four pictures $(N=1072)$

\begin{tabular}{c|c|c|c}
\hline Between & $C R$ & Between & $C R$ \\
\hline Picture 1 and 2 & 3.99 & Picture 2 and 3 & 3.68 \\
, 1 and 3 & 7.64 &, 2 and 4 & 8.84 \\
1 and 4 & 12.70 & " 3 and 4 & 5.20
\end{tabular}

All the $C R$ s are significant far beyond .001 level.

empirically. One hundred and twenty Marathi stories written under Neutral condition by subjects in the present investigation were translated into English by a competent translator. When the number of words in these stories in both the languages was counted, it was found that the mean number of words per story in English was significantly greater $(C R=5.13, p<$ $.01)$ than the mean number of words per story in Marathi. This meant that it took more words in English to translate neatly the Marathi stories. Precisely, all this only reinforces our earlier contention that the present boys have written quite longer stories than the subjects of Veroff et al. (1960).

One more point is about the adequacy of the time allotted for writing a story. Sometimes it is suggested that $4 \frac{1}{2}$ minutes is not sufficient for high school boys for writing a projective story. However, the above results show that this much time is quite adequate and the suggestion need not be taken very seriously.

\section{Cue Value of Pictures}

In order to study the cue characteristics of pictures, the percentages of achievement -related (AI) stories and the mean $n$ Ach score of stories on each of the four pictures were found out which are given in Table 5 .

The table shows that the "Inventors" picture has elicited the maximum amount of achievement imagery and the highest $\mathrm{n}$ Ach score, then comes the "Boy in checked shirt," third is the "Father-son," and the last comes the "Operation scene" picture having the lowest mean $\mathrm{n}$ Ach score. This order is very much in agreement with the findings of previous researchers (e.g., McGlelland et al., 1953 ; Jacobs, 1958 ; Birney, 1958) who have reported the "Inventors" as a high cue picture, and "Father -son" and the "Operation scene" as low cue pictures. The significance of the differences between every two percentages of AI is given in Table 6 which shows that all the six $C R$ s are very highly significant, and that the four pictures really differ from one another in their cue value.

Admittedly, no method which is independent of the $n$ Ach scoring procedure has been used; yet the results have a close similarity with those obtained by other methods - either dependent on or indepen- 
dent of the scoring system-for investigating the cue characteristics of pictures. This naturally leads us to the problem of "culturally defining" certain pictures or situations as having or not having achievement-related cues for a given society. If the 'workshop scene' represents an achievement situation in American culture, it does not in any way represent a lesser achievement situation in present day urban Indian culture. India does not seem to remain a "different" culture in the sense that the values of modern science have been, and are still rapidly being internalized as her own. It is therefore natural that a picture which elicits greater achievement imagery in stories of American subjects, also elicits greater achievement imagery in stories written by Indian subjects.

One subtle point that cannot escape attention is the relationship between the order of presentation of pictures and the decreasing achievement imagery for the four pictures as the test proceeds. The serial position effect has not been systematically investigated in this study, nor any sawtooth phenomenon observed. Ostensibly it can be said that the decreasing achievement imagery is primarily a function of the cue value of pictures, and not of the serial position, since 20 minutes was not so long a time as to exhaust the achievement imagery of the subjects or to bring them to a refractory phase. The fact that the boys have written longer stories toward the end of the test may support this argument.

\section{Analysis of Subcategories}

The purpose of such an analysis was to study the composition of the measured $n$ Achievement and to see whether this composition differed in some remarkable way from the composition other researchers have observed. The total number of stories obtained under Neutral condition was $(1072 \times 4=)$ 4288. Taking this as $100 \%$ the percentages of UI, TI, and AI were calculated, and are given in Table 7.

The number of achievement-related (AI)
TABLE 7

Percentages of achievement-related categories and subcategories in stories written under neutral condition in this investigation, and such percentages obtained by Mehta (1967)

\begin{tabular}{l|c|c}
\hline Category & Percentage & $\begin{array}{c}\text { Percentage } \\
\text { Mehta }(1967)\end{array}$ \\
\hline UI & 23.72 & 14.31 \\
TI & 38.13 & 46.35 \\
AI & 38.15 & 39.34 \\
\hline Total & 100.00 & 100.00 \\
Subcategory & & \\
N & 35.15 & 73.18 \\
I+ & 61.43 & - \\
I? & 12.10 & - \\
I- & 2.14 & - \\
I (comb.) & $(75.67)$ & $(76.30)$ \\
Ga+ & 2.87 & 7.12 \\
Ga- & 12.22 & 2.60 \\
Bp & 8.07 & 1.74 \\
Bw & 9.23 & 1.13 \\
Nup & 4.34 & 0.39 \\
G+ & 28.79 & 8.42 \\
G- & 12.16 & 0.65 \\
Ach Th & 78.24 & 64.28 \\
& & \\
\hline
\end{tabular}

stories was 1636 , and now taking this number as $100 \%$, percentages of all the remaining subcategories were calculated which are given in the same table. (It is recalled that only those stories which were scored for achievement imagery were further scored for other subcategories.) The last column of the table gives for comparison percentages of subcategories observed by Mehta (1967).

From Table 7 it is seen that instrumental activity $(\mathrm{I}+, \mathrm{I}$ ?, and $\mathrm{I}-$ ) and achievement thema (Ach $\mathrm{Th}$ ) have occurred in more than three-fourths of the stories, thus maximally contributing to the $\mathrm{n}$ Ach score. Regarding instrumental activity, McClelland's (1961) observation that achievement-related stories in readers from more rapidly developing countries (which included India) gave more "successful instrumental activity" meaning that the 
higher $\mathrm{n}$ Achievement is "means" oriented, is strongly supported by the present results $(\mathrm{I}+$ : 61.43).

Comparing the obtained percentages of subcategories with Mehta's (1967) as given in Table 7, a close agreement in respect of $\mathrm{AI}$ and I categories, some agreement in respect of Ach Th, and a good deal of divergence in respect of many of the remaining subcategories is observed. It is rather difficult to explain this divergence since both the studies have been conducted with male high school subjects in prominent Indian cities. The differences may be due to expressive power of the two languages Marathi and Hindi, due to the scoring procedures, due to the type of pictures used (Mehta had used line drawings presented in book form), or due to one or more of such reasons. However, some general comments may be offered. Mehta (1967) reports that the negative categories like $\mathrm{Ga}-, \mathrm{G}-, \mathrm{Bp}, \mathrm{Bw}$ etc. are almost absent from the stories of his subjects, but this is not the case in the present study. The socalled negative subcategories are definitely there, though not in great quantities. The probe into the theoretical implications of the absence of subcategories as suggested by Mehta will have, therefore, to be preceded by the gathering of more research data on the point at issue.

\section{REFERENGES}

Atrinson, J. W. 1950 Studies in projective measurement of achievernent motivation. Unpublished doctorral dissertation, Univ. of Michigan. From McClelland et al., 1953.

Atrinson, J. W. (Ed.) 1958 Motives in fantasy, action, and society. Princeton: Van Nostrand.

BIRNEY, R. C. 1958 Thematic content and the cue characteristics of pictures. In Atkinson, J.W. (Ed.), Motives in fantasy, action, and society. Princeton: Van Nostrand.

Child, I. L., Storm, T., \& Veroff, J. 1958 Achievement themes in folk tales related to socialization practice. In Atkinson, J.W. (Ed.), Motives in fantasy, action, and society.
Princeton: Van Nostrand.

Haber, R. N., \& Alpert, R. 1958 The role of situation and picture cues in projective measurement of the achievement motive. In Atkinson, J. W., Motives in fantasy, action, and society. Princeton: Van Nostrand.

JACoBs, B. J. 1958 A method for investigating the cue characteristics of pictures. In Atkinson, J. W. (Ed.), Motives in fantasy, action, and society. Princeton: Van Nostrand.

Lesser, G. S., Krawitz, Rhoda N., \& Packard, Rita 1963 Experimental arousal of achievement motivation in adolescent girls. f. abnorm. soc. Psychol., 66, 59-66.

MaClelland, D. C. 1961 The achieving society. Princeton: Van Nostrand.

McGlelland, D. C., Atkinson, J.W., Clark, R. A., \& Lowelt, E. L. 1953 The achievement motive. New York: Appleton-CenturyCrofts.

Mehta, Prayag 1967 Achievement motive in high school boys. (A report of the research project at Delhi, in press.)

Ricciuti, H. N., \& Clark, R. A. 1954 A comparison of need achievement stories written by experimentally "relaxed" and "achievement- oriented" subjects: effects obtained with new pictures and revised scoring categories. Princeton: Educational Testing Service.

Ricciutr, H. N., \& SADACCA, R. 1955 The prediction of academic grades with a projective test of achievement motivation. II. Cross validation at the high school level. Princeton: Educational Testing Service.

Scott, W. A. 1956 The avoidance of threatening material in imaginative behavior. 7 . abnorm. soc. Psychol., 52, 338-346.

TAMHANKar, V.S. 1967 A study of achievement motivation among the young adolescent boys in Poona city. Unpublished Ph. D. thesis. Univ, of Poona, India.

Veroff, J., Athinson, J., Feld, Sheila, \& Gurin, G. 1960 The use of thematic apperception to assess motivation in a nationwide interview study. Psychol. Monogr., 74, Whole No. 499.

Walker, E. L., \& Atkinson, J. W. 1958 The expression of fear-related motivation in thematic apperception as a function of proximity to an atomic explosion. In Atkinson, J. W. (Ed.), Motives in fantasy, action, and society. Princeton: Van Nostrand.

(Received May 1, 1968) 